\title{
Chemical Compositions and Antimicrobial Activities of Ocimum sanctum L. Essential Oils at Different Harvest Stages
}

\author{
Mohammad Jamal Saharkhiz ${ }^{1}$; Amir Alam Kamyab ${ }^{2}$; Narges Khatoon Kazerani ${ }^{3}$; Kamiar \\ Zomorodian $^{4,5,}$; Keyvan Pakshir ${ }^{4,5}$; Mohammad Javad Rahimi ${ }^{5}$ \\ ${ }^{1}$ Department of Horticultural Sciences, Shiraz University, Shiraz, IR Iran \\ ${ }^{2}$ Student Research Committee, Shiraz University of Medical Sciences, Shiraz, IR Iran \\ 3 Agricultural Research Center, Borazjan, IR Iran \\ ${ }_{4}$ Basic Science in Infectious Diseases Research Center, Shiraz University of Medical Sciences, Shiraz, IR Iran \\ 5 Department of Medical Mycology and Parasitology, Shiraz University of Medical Sciences, Shiraz, IR Iran \\ ${ }^{*}$ Corresponding author: Kamiar Zomorodian, Basic Science in Infectious Diseases Research Center, Shiraz University of Medical Sciences, P. O. Box: 7134845794, Shiraz, IR Iran. Tel: \\ +98-9177144094, Fax:+98-7112305291, E-mail:zomorodian@sums.ac.ir, kzomorodian@gmail.com
}

Received: July 20, 2013; Revised: September 28, 2013; Accepted: October 9, 2013

\begin{abstract}
Background: Essential Oils (EOs) possess antibacterial properties and represent a natural source to treat infections and prevent food spoilage. Their chemical composition might be affected by the environmental condition and the developmental growth stages of the plant.

Objectives: The current study aimed to determine the variations in chemical compositions and antimicrobial activities of the EOs of Ocimum sanctum $\mathrm{L}$. at different stages of harvesting.

Materials and Methods: The oils constituents were analyzed by gas chromatography/mass spectrometry (GC/MS). The effects of three different harvest stages of $O$. sanctum EOs against most common causes of food-borne were evaluated by broth micro-dilution method as recommended by the Clinical and Laboratory Standards Institute (CLSI).

Results: The analysis of the EOs indicated that eugenol was the major compound of the EOs at all developmental stages which reached its maximum level at the second stage. The results showed that the tested EOs exhibited antimicrobial activities against all of the examined pathogens at concentrations of $0.125-32 \mu \mathrm{L} / \mathrm{mL}$, except Pseudomonas aeruginosa which was only inhibited by high concentrations of the floral budding and full flowering EOs. EO distilled from the second developmental growth stage (floral budding) of 0 . sanctum exhibited the strongest antibacterial activities against the food borne bacteria.

Conclusions: Considering the wide range of antimicrobial activities of the examined EOs, they might have the potential to be used to manage infectious diseases or extend the shelf life of food products.
\end{abstract}

Keywords: Essential Oil; Eugenol; Anti-Infective Agents Fungi; Ocimum Sanctum Linn; Foodborne Diseases Food-Borne Infection

\section{Background}

Foods provide a suitable media for many microorganisms to grow and produce byproducts and metabolites. Consumption of the contaminated food with a toxin or secondary metabolite due to bacterial growth in food, such as Staphylococcus aureus or Aspergillus species, is called food poisoning. On the other hand, certain types of live bacteria such as Entrobacteriacea family might be transmitted through eating contaminated foods and cause food-borne infection. Contaminated foods are among the main concerns of the public health policy makers and food industries. Traditionally, in tropical areas where the food-borne infections are more frequent, the aromatic plants and spices are used in foodstuff for their flavoring and preservative properties (1-4). It is observed that many of these plants and their aromatic products have potential antimicrobial activities (5-8). In the recent decades, there is a global tendency to use organic and chemical-free foodstuffs. The use of aro- matic plants with known medicinal and antimicrobial properties might be a solution to increase the shelf life of products or overcome antibiotic resistance (8).

Parallel to the invention of new generations of antibiotics, clinicians encounter antibiotic resistance which has dramatically increased during the recent years. This problem is increasing worldwide, imposing a huge burden of costs, morbidity, and mortality. Therefore, it is necessary to find new antimicrobial agents to apply in the cases of antibiotic resistance. Methicillin-resistant S. aureus (MRSA), vancomycin-resistant Enterococcus (VRE) species, third-generation cephalosporin-resistant (TGCsR) Escherichia coli, imipenem and quinolone-resistant Pseudomonas aeruginosa, antibacterial-resistant Salmonella and Shigella species are the top resistant pathogens. Plants and their Eos are among the resources of new anti-microbial compounds. The number of studies on antimicrobial activities of plant compounds

Copyright (C) 2015, Ahvaz Jundishapur University of Medical Sciences. This is an open-access article distributed under the terms of the Creative Commons Attribution-NonCommercial 4.0 International License (http://creativecommons.org/licenses/by-nc/4.0/) which permits copy and redistribute the material just in noncommercial usages, provided the original work is properly cited. 
against many different types of microbes, including food-borne pathogens has increased in the recent decades.

Ocimum sanctum L. (Tulsi in Sanskrit or Reyhan-eMoghaddas in Farsi) belonging to Lamiaceae family, is native to Asia, and Central and western parts of Africa. Tulsi is traditionally used as a medicinal plant (9). Pharmacological studies and clinical practices have demonstrated that this species possesses anti-oxidative $(10,11)$ and antimicrobial functions including antibacterial (9,12), antifungal (13-15), antimalarial (9) and antihelminthic (16). It has been also recommended to treat diabetes, bronchitis, diarrhea, dysentery, dyslipidemia, hypertension and skin diseases $(9,17,18)$.

Chemical and biological diversity of the aromatic and medicinal plants differ significantly depending on the factors such as cultivation area, climatic conditions, genetic modification, different plant parts, developmental stages and collection time (19-21). In the recent years, numerous publications have reported the chemical compositions of the EOs of medicinal and aromatic plants demonstrating that the growth stage and harvesting time have a major impact on the EO content and compositions (21-23). Therefore, it is necessary to determine the proper time and plant growth phase to harvest by analyzing the EO and its compositions at various growth and developmental stages. To the best of authors` knowledge, literature pertaining to the EO content and composition of Tulsi from Iran is not available. Moreover, there is no report on EO compositions of Tulsi at different collection time such as vegetative, floral budding and flowering stages. It is, therefore, imperative to determine the appropriate harvesting time by analyzing the oil yield and composition of the plant.

\section{Objectives}

The current study, for the first time, aimed to assess the EO content and chemical constituents of three different growth and developmental stages of 0 . sanctum. In addition, the antimicrobial effects of these EOs were evaluated against standard strains and clinical isolates responsible for food borne infections.

\section{Materials and Methods}

\subsection{Plant Material}

This experiment was carried out in Agricultural Research Center of Bushehr province, located in nine miles South-east of Borazjan, Iran, with an altitude of 110 meters, $51^{\circ} 17^{\prime}$ longitude and $21^{\circ} 2^{\prime}$ latitude in a 1350 square meters land, which was a fallow land last year. The average annual rainfall in this region is 300 to 350 $\mathrm{mm}$, the maximum temperature is $51^{\circ} \mathrm{C}$ in August, and minimum temperature is $-1^{\circ} \mathrm{C}$ in February. Some chemical characteristics of the experimental soils are shown in Table 1. Ocimum sanctum aerial parts were collected from the cultivated plants at three stages of growth and development during June and July 2012. The samples were harvested at vegetative, floral budding (emergence of flower buds) and full flowering stages. A voucher specimen (HSU 24989) is deposited in the herbarium of Shiraz University, Shiraz, Iran.

Table 1. Some Chemical Characteristics of the Experimental Soil ${ }^{\text {a }}$

\begin{tabular}{|c|c|}
\hline Variable & Value \\
\hline EC, $\mathrm{dS}^{-1}$ & 1.8 \\
\hline pH & 7.5 \\
\hline O.M, \% & 0.97 \\
\hline T.N, \% & 0.53 \\
\hline$P, \mathrm{mg} \mathrm{kg}^{-1}$ & 13.5 \\
\hline $\mathrm{K}, \mathrm{mg} \mathrm{kg}^{-1}$ & 540 \\
\hline $\mathrm{Cu}, \mathrm{mg} \mathrm{kg}^{-1}$ & 1.1 \\
\hline $\mathrm{Fe}, \mathrm{mg} \mathrm{kg}^{-1}$ & 4.9 \\
\hline $\mathrm{Zn}, \mathrm{mg} \mathrm{kg}^{-1}$ & 0.234 \\
\hline Mn, $\mathrm{mg} \mathrm{kg}^{-1}$ & 0.394 \\
\hline
\end{tabular}

a Abbreviations: EC, electrical conductivity; O.M, organic matter; T.N, total nitrogen.

\subsection{Essential Oils Preparation}

At the above-mentioned developmental stages, the essential oil of the aerial parts of the 0 . sanctum ( $50 \mathrm{~g}$ for each stage) was obtained by hydrodistillation for 2.5hours, using an all-glass Clevenger-type apparatus, according to the protocol outlined by the British Pharmacopoeia (24). The sample oils were dried over anhydrous sodium sulphate and stored in sealed vials at $4^{\circ} \mathrm{C}$ before gas chromatography (GC) and gas chromatography/mass spectrometry (GC-MS) analysis and antimicrobial assessments.

\subsection{Essential Oils Analysis by Gas Chromatogra- phy/Mass Spectrometry (GC/MS)}

The EOs were analyzed by GC-MS (Agilent, USA). The analysis was carried out on a Thermoquest-Finnigan Trace GC/MS instrument equipped with a DB-5 fused silica column $(60 \mathrm{~m} \times 0.25 \mathrm{~mm}$ i.d., film thickness $0.25 \mathrm{~mm}$ ). The oven temperature was programmed to increase from 60 to $250^{\circ} \mathrm{C}$ at a rate of $4^{\circ} \mathrm{C} /$ minute and finally held for 10 minutes; transfer line temperature was $250^{\circ} \mathrm{C}$. Helium was used as the carrier gas at a flow rate of $1.1 \mathrm{~mL} /$ minute, with a split ratio equal to $1: 50$. The quadrupole mass spectrometer was scanned over the 35-465 amu with an ionizing voltage of $70 \mathrm{eV}$ and an 
ionization current of $150 \mathrm{~mA}$.

GC-FID analysis of the oil was conducted using a Thermoquest-Finnigan instrument equipped with a DB-5 fused silica column ( $60 \mathrm{~m}$ x $0.25 \mathrm{~mm}$ i.d., film thickness $0.25 \mathrm{~mm}$ ). Nitrogen was used as the carrier gas at the constant flow of $1.1 \mathrm{~mL} /$ minute; the split ratio was the same as that of GC/MS. The oven temperature was raised from 60 to $250^{\circ} \mathrm{C}$ at a rate of $4^{\circ} \mathrm{C} /$ minute and held for 10 minutes. The injector and detector (FID) temperatures were kept at 250 and $280^{\circ} \mathrm{C}$, respectively. Semiquantitative data were obtained from FID area percentages without the use of correction factors.

\subsection{Identification of EO Components}

Retention indices (RI) were calculated by using retention times of n-alkanes (C6-C24) that were injected after the oil at the same temperature and conditions. The compounds were identified by comparison of their RI with those reported in the literature (25) and their mass spectrum was compared with the Wiley Library.

\subsection{Determination of Antimicrobial Activities}

\subsubsection{Microorganisms}

The antifungal activities of the EOs were determined against five standard strains of fungi including Aspergillus flavus (ATCC 64025), A. fumigatus (ATCC 14110 and CBS 144.89), A. clavatus (CBS 514.65) and A. orizae (CBS 818.72). The antibacterial activities of the EOs against standard species of Staphylococcus aureus (ATCC 25923 and ATCC 29213), Enterococcus faecalis (ATCC11700), Escherichia coli (ATCC 25922), enterohemorrhagic E. coli (ATCC 43894), Pseudomonas aeruginosa (ATCC 27853) and a clinical isolate of Shigella flexneri collected from the Dr. Faghihi Hospital (Shiraz, Iran) were also determined in this study.

\subsubsection{Determination of Minimum Inhibitory Concen- tration (MIC)}

MICs were determined using the broth microdilution method recommended by the CLSI $(26,27)$ with some modifications. Briefly, to determine antifungal activities, serial dilutions of the EOs (0.06-64.0 $\mu \mathrm{L} / \mathrm{mL})$ were prepared in 96-well microtitre plates using RPMI-1640 media (Sigma, St. Louis, USA) buffered with MOPS (Sigma, St. Louis, USA). To determine the antibacterial activities, serial dilutions of the EOs (0.06-64.0 $\mu \mathrm{L} / \mathrm{mL})$ were prepared in Muller-Hinton media (Merck, Darmstadt, Germany). Test fungi or bacteria strains were suspended in the media and the cell densities were adjusted to 0.5 McFarland standards at $530 \mathrm{~nm}$ wavelength using the spectrophotometric method (this yields stock suspension of $1-5 \times 10^{6}$ cells/mL for fungi and 1-1.5 $\times$ $10^{8}$ cells/mL for bacteria). To each well of the micotiter plates, $0.1 \mathrm{~mL}$ of the working inoculums was added and the plates were incubated in a humid atmosphere at $30^{\circ} \mathrm{C}$ for $24-48$ hours for yeasts or at $37^{\circ} \mathrm{C}$ for 24 hours for bacteria. To provide control (blank) samples, 200 $\mu \mathrm{L}$ of un-inoculated medium was included. In addition, growth controls (medium with inoculums, without EO) were also included.

The growth in each well was compared with that of the growth control well. MICs were visually determined and defined as the lowest concentration of the EO produced $\geq 50 \%$ growth inhibition for fungi and $\geq$ 95\% growth reduction for bacteria compared with the growth control wells. Each experiment was performed in triplicate. In addition, media from wells with fungi showing no visible growth were further cultured on Sabouraud dextrose agar (Merck, Darmstadt, Germany) and from wells with bacteria showing no visible growth on Muller-Hinton agar (Merck, Darmstadt, Germany) to determine the minimum fungicidal concentration (MFC) and minimum bactericidal concentration (MBC), respectively.

\section{Results}

The hydro-distillation of the aerial parts of 0 . sanctum at the vegetative, floral budding, and full flowering stages yielded $0.98 \%, 0.92 \%$ and $1.1 \%(w / w)$ EO, respectively. The composition of EOs at different growth stages is shown in Table 2, in the order of their elution from a DB-5 column. A total of 13, 15 and 15 compounds representing $88.44 \%, 95.09 \%$ and $92.21 \%$ of the total were detected at vegetative, floral budding and full flowering stages, respectively. GC/MS analyses showed that the main constituents of the EO from the vegetative stage were 1,8 -Cineole and $\beta$-bisabolen, while eugenol was found as the main compound of floral budding and full flowering developmental stages.

The antibacterial activities of $O$. sanctum EOs against the tested bacteria are presented in Table 3. The EOs inhibited the growth of Gram-positive cocci at the concentrations of $0.5-32 \mu \mathrm{L} / \mathrm{mL}$ and removed them at the concentrations ranging from 1 to $32 \mu \mathrm{L} / \mathrm{mL}$. Furthermore, the EOs exhibited anti-bactericidal activity (MBC) against all of the above-mentioned Gram-positive cocci at the concentrations ranging from 8 to 32 $\mu \mathrm{L} / \mathrm{mL}$, except the vegetative growth stage against $E$. faecalis. The 0 . sanctum EOs inhibited the growth of all Gram-negative bacteria at the concentrations of 0.25-4 $\mu \mathrm{L} / \mathrm{mL}$, except $P$. aeruginosa. The growth of $P$. aeruginosa was inhibited only in concentrations $\geq 64 \mu \mathrm{L} / \mathrm{mL}$. The EOs exhibited anti-bactericidal activity (MBC) against all the above-mentioned Gram-negative bacteria at concentrations ranging from 0.5 to $\geq 64 \mu \mathrm{L} / \mathrm{mL}$. The antimicrobial activities of $O$. sanctum EOs against the tested fungi are shown in Table 3. The essence of 0 . sanctum at different growth stages exhibited fungiostatic and fungicidal activities against the Aspergillus species at the concentrations of $0.125-2 \mu \mathrm{L} / \mathrm{mL}$ and $0.125-4 \mu \mathrm{L} / \mathrm{mL}$, 
respectively.

Table 2. Chemical Components of the Essential Oils Distilled From Three Developmental Stages of Ocimum sanctum ${ }^{\text {a }}$

\begin{tabular}{|c|c|c|c|c|}
\hline \multirow[t]{2}{*}{ Compound } & \multicolumn{4}{|c|}{ Developmental Stages, \% } \\
\hline & RI & Vegetative & Floral Budding & Full Flowering \\
\hline Ethyl Isovalerate & 854 & - & - & 0.83 \\
\hline$\alpha$-Pinene & 954 & 0.76 & 0.41 & 0.66 \\
\hline Sabinen & 985 & 0.55 & 0.44 & 0.49 \\
\hline$\beta$-Pinene & 1010 & 1.08 & 1.53 & 1.73 \\
\hline Myrcene & 1059 & 0.53 & 1.128 & 0.93 \\
\hline 1,8-Cineole & 1068 & 20.78 & 19.41 & 20.45 \\
\hline Linalool & 1109 & 0.22 & 0.19 & 0.15 \\
\hline Terpinen-4-ol & 1184 & - & 0.28 & - \\
\hline a-Terpineol & 1211 & - & 0.37 & 0.42 \\
\hline Estragol & 1229 & 11.49 & 10.61 & 11.40 \\
\hline Eugenol & 1382 & 15.70 & 37.15 & 24.63 \\
\hline$\alpha$-Cis-Bergamotene & 1469 & 3.13 & 1.30 & 2.69 \\
\hline$\alpha$-Humlene & 1482 & 2.34 & 1.29 & 1.27 \\
\hline$\beta$-Bisabolen & 1542 & 20.99 & 13.29 & 18.76 \\
\hline$\gamma$-Elemene & 1565 & 10.47 & 7.7 & 7.8 \\
\hline
\end{tabular}

a abbreviation: RI, retention index.

Table 3. Antimicrobial Activity of OcimumSanctum Essential Oil Against Standard and Clinical Isolates of Bacteria and Aspergillus spp. ${ }^{a}$

\begin{tabular}{|c|c|c|c|c|c|c|}
\hline \multirow[t]{2}{*}{ Bacteria } & \multicolumn{2}{|c|}{ Vegetative Stage } & \multicolumn{2}{|c|}{ Floral Budding Stage } & \multicolumn{2}{|c|}{ Full Flowering Stage } \\
\hline & MIC & MMC & MIC & MMC & MIC & MMC \\
\hline \multicolumn{7}{|l|}{ Gram positive } \\
\hline S. aureus & 1 & 16 & 0.5 & 8 & 1 & 8 \\
\hline S. aureus & 8 & 32 & 2 & 16 & 1 & 8 \\
\hline E.faecalis & 32 & $>64$ & 4 & 8 & 16 & 32 \\
\hline B. cereus & 2 & 8 & 0.5 & 4 & 0.5 & 2 \\
\hline \multicolumn{7}{|l|}{ Gram negative } \\
\hline E. coli & 4 & 8 & 1 & 2 & 2 & 4 \\
\hline E. coli 0157 & 4 & 8 & 1 & 2 & 1 & 2 \\
\hline P. aeruginusa & $>64$ & $>64$ & 64 & 64 & 64 & $>64$ \\
\hline Shigella flexneri & 2 & 2 & 0.25 & 0.5 & 0.25 & 0.5 \\
\hline \multicolumn{7}{|l|}{ Fungi } \\
\hline A. flavus & 2 & 4 & 0.5 & 1 & 0.25 & 0.5 \\
\hline A. fumigatus 1 & 1 & 4 & 0.25 & 1 & 0.125 & 0.5 \\
\hline A. fumigatus 2 & 1 & 4 & 0.25 & 1 & 0.125 & 0.5 \\
\hline A.clavatus & 1 & 2 & 0.25 & 0.5 & 0.125 & 0.125 \\
\hline A. orizae & 1 & 4 & 0.5 & 1 & 0.25 & 0.5 \\
\hline
\end{tabular}

a Abbreviations: MIC, minimum inhibitory concentration; MMC, minimum antimicrobial concentration.

\section{Discussion}

EOs and their components are generally recognized as safe (GRAS) for human and animal consumption under US Federal Regulations and have antimicrobial activity against a wide variety of foodborne pathogens. The current study showed anti-bacterial and anti-fungal characteristics of a traditional plant called $O$. sanctum on 
food-borne Gram-positive, Gram-negative bacteria and Aspergillus species. The compositions of EOs might be affected by the developmental stage of the plant $(6,28)$. Although some authors reported Methyl Chavicol (14, 29) as the major compounds of the EO, others reported eugenol as the main constituent of the EO $(13,16)$. In the present study, $\beta$-bisabolen was the dominant compound of the oil at the vegetative stage which declined gradually from $20.99 \%$ to $13.29 \%$ at the floral budding stage. Eugenol which reached its maximum level at the floral budding stage was identified as the main compounds of both floral budding and full flowering stages. The lower concentration of eugenol in this study, compared with that of some previous reports $(13,16)$, may reflect variations due to geographical location. During the various developmental stages of 0 . sanctum, the concentration of 1, 8-Cineole gradually declined from $20.78 \%$ to $20.45 \%$.

The antimicrobial activity of 0 . sanctum against some microorganisms has been investigated in some previous studies (12). Agarwal et al. in an experimental study demonstrated that $O$. sanctum extract was effective against Streptococcus mutans (12). Others showed antimicrobial properties of the extract of this plant against $S$. aureus and enteric bacteria (30). In another study, its efficacy against multi-resistant strains of Neisseria gonorrhea was demonstrated (31). In the present study, the EOs inhibited the growth of all Gram-positive bacteria and removed them at the concentrations up to $32 \mu \mathrm{L} / \mathrm{mL}$, , except $E$. faecalis. Similar to the previous studies (30), nearly all the studied Gram-negative bacteria were susceptible to EOs of this plant at the concentrations of $0.25-4 \mu \mathrm{L} / \mathrm{mL}$, except $P$. aeruginosa which was only inhibited by high concentrations of the floral budding and full flowering EOs. This bacterium is a well-known nosocomial and burn wound pathogen. It has a low susceptibility to many antibiotics which is caused by the action of multidrug efflux pumps and the low permeability of its outer membrane (32). The higher MICs of the EOs against P. aeruginosa in comparison with the other bacteria might be attributable to the presence of some constructive proteins (such as Protein F) in its outer membrane (32).

The antimicrobial properties of 0 . sanctum are not confined to bacteria. It possesses anti-fungal and antihelmintic activities. Of Aspergillus species, A. flavus and A. parasiticus are responsible for producing a number of secondary metabolites including aflatoxins. These secondary by-products are well-known for carcinogenic, mutagenic and teratugenic effects on humans and animals (33). In addition, Aspergillus species, in particular $A$. fumigates and $A$. flavus, are responsible for severe invasive infections especially in immuocompromised hosts (34). Antifungal activities of the 0 . sanctum against Candida spp. and dermatophytes were previously indicated $(6,14$, 15). In the current study, the developmental growth stages of the EOs, in particular full flowering stage, exhibited significant fungistatic and fungicidal activities against Aspergillus species. These results support the previously reported data (13), and suggest that the EO of 0 . sanctum has the potential to be used in the food industries as preservative to prevent the growth of aflatoxicogenic fungi.

Since the EOs exhibited similar antimicrobial effect. One of the main characteristics of EOs is their hydrophobicity, which enables their incorporation into the cell membrane (35). Of the developmental stages, the second stage was more potent against most of the examined bacteria. Its mechanism may yield behind the active ingredients of 0 . sanctum, since biological activity of the EOs is determined by its various chemical constituents. The most potent antibacterial component of 0 . sanctum in the second stage was eugenol and the noticeable antibacterial properties of this stage might be related to this compound. Eugenol is a phenylpropanoid compound used in perfumes and flavorings as well as medicines as an antiseptic and anesthetic.

Antimicrobial activities of eugenol were shown previously (36-42). Eugenol inhibited the growth of Helicobacter pylori strains at a concentration of $2 \mu \mathrm{g} / \mathrm{mL}$ (36). Eugenol was found to be effective against Listeria monocytogenes, Aeromonas hydrophila and autochthonous spoilage flora in microbial media (37). In other studies, eugenol exhibited strong antimicrobial activities against E. coli, S. aureus, Bacillus cereus, L. monocytogenes, P. aeruginosa, Salmonella typhi, and Proteus mirabilis (40-42). It has also been used in mucoadhesive tablets to treat periodontal diseases (38). An important characteristic of eugenol is its hydrophobicity which enhances its incorporation into the cell membrane.

It is proposed that the effective microbial damage of this molecule might be due to disruption of bacterial cell membrane $(41,42)$, which leads to increased cell membrane permeability and protein leakage (39). Other possible mechanisms of antimicrobial action of eugenol are conversion of cytochrome P-450 mediated into cytotoxic quinine methide $(40,43,44)$ and inhibition of energy generation (45). Other ingredients of the EOs with significant antibacterial potency were cineol and $\beta$-bisabolen. These two latter ingredients had higher concentrations at the vegetative stage than the other stages. Synergistic activity of the combination of ampicillin with $\beta$-bisabolen against $S$. aureus was confirmed by previous studies (4648). Moreover, it was shown that 1, 8-cineol has significant antimicrobial activities alone or in combination with other monoterpens or drugs (49). All together, these facts and results support the broad spectrum antimicrobial activities of $O$. sanctum EO by the mechanisms different from those of the antibiotics, and its possible application in the cosmetic, medicinal and food products.

Chemical composition and subsequent biological activities of EOs are not only determined by the origin and environmental conditions, but also by developmental stage in which the plant is collected. The EO distilled from the second developmental growth stage of 0 . sanctum (floral budding) exhibited strong antibacterial activities against several food-borne bacteria as well as Aspergillus 
species. Therefore, any attempts for clinical or industrial application of this EO should focus on the second developmental stage and its major ingredient (i.e. eugenol). Regarding the considerable antibacterial activities of the tested EOs, they might be the candidates to develop new antibiotics and disinfectants to control infective agents. The desirable flavor and odor of this EO at the examined concentrations is an additional benefit to its antimicrobial activities which makes it a suitable candidate to be used as a food preservative.

\section{Authors' Contributions}

Study concept and design: Kamiar Zomorodian; sample collection and laboratory examinations: Amir Alam Kamyab, Mohammad Javad Rahimi, Keyvan Pakshir, Narges Khatoon Kazerani; data interpretation: Keyvan Pakshir, Kamiar Zomorodian, Mohammad Jamal Saharkhiz; manuscript: Kamiar Zomorodian, Amir Alam Kamyab and Mohammad Jamal Saharkhiz; Critical revision of the manuscript for important intellectual content: All the Authors.

\section{Funding/Support}

This study is part of the MD thesis of Amir A'lam Kamyab. The study was financially supported by Shiraz University of Medical Sciences (Grant No. 90-01-43-2979). The funding organization is Shiraz University of Medical Sciences, which had no role in the design and conduct of the study; collection, management, and analysis of the data; or preparation, review, and approval of the manuscript.

\section{References}

1. Tapsell LC, Hemphill I, Cobiac L, Patch CS, Sullivan DR, Fenech M, et al. Health benefits of herbs and spices: the past, the present, the future. Med JAust. 2006;185(4 Suppl):S4-24.

2. Aggarwal BB, Sundaram C, Malani N, Ichikawa H. Curcumin: the Indian solid gold. Adv Exp Med Biol. 2007;595:1-75.

3. Billing J, Sherman PW. Antimicrobial functions of spices: why some like it hot. Q Rev Biol.1998;73(1):3-49.

4. Sherman PW, Hash GA. Why vegetable recipes are not very spicy. Evol Hum Behav. 2001;22(3):147-63.

5. Zomorodian K, Saharkhiz MJ, Rahimi MJ, Bandegi A, Shekarkhar G, Bandegani A, et al. Chemical composition and antimicrobial activities of the essential oils from three ecotypes of Zataria multiflora. Pharmacogn Mag. 2011;7(25):53-9.

6. Saharkhiz MJ, Zomorodian K, Rezaei MR, Saadat F, Rahimi MJ. Influence of growth phase on the essential oil composition and antimicrobial activities of Satureja hortensis. Nat Prod Commun. 2011;6(8):1173-8.

7. Zomorodian K, Moein M, Lori ZG, Ghasemi Y, Rahimi MJ, Bandegani A, et al. Chemical Composition and Antimicrobial Activities of the Essential Oil from Myrtus communis Leaves. Journal of Essential Oil Bearing Plants. 2013;16(1):76-84.

8. Ricke SC, Kundinger MM, Miller DR, Keeton JT. Alternatives to antibiotics: chemical and physical antimicrobial interventions and foodborne pathogen response. Poult Sci. 2005;84(4):667-75.

9. Prakash P, Gupta N. Therapeutic uses of Ocimum sanctum Linn (Tulsi) with a note on eugenol and its pharmacological actions: a short review. Indian J Physiol Pharmacol. 2005;49(2):125-31.

10. Shah K, Verma RJ. Protection against butyl p-hydroxybenzoic acid induced oxidative stress by Ocimum sanctum extract in mice liver. Acta Pol Pharm. 2012;69(5):865-70.

11. Ahmad A, Rasheed N, Chand K, Maurya R, Banu N, Palit G. Re- straint stress-induced central monoaminergic \& oxidative changes in rats \& their prevention by novel Ocimum sanctum compounds. Indian J Med Res. 2012;135(4):548-54.

12. Agarwal P, Nagesh L, Murlikrishnan.. Evaluation of the antimicrobial activity of various concentrations of Tulsi (Ocimum sanctum) extract against Streptococcus mutans: an in vitro study. Indian J Dent Res. 2010;21(3):357-9.

13. Kumar A, Shukla R, Singh P, Dubey NK. Chemical composition, antifungal and antiaflatoxigenic activities of Ocimum sanctum $\mathrm{L}$. essential oil and its safety assessment as plant based antimicrobial. Food Chem Toxicol. 2010;48(2):539-43.

14. Khan A, Ahmad A, Akhtar F, Yousuf S, Xess I, Khan LA, et al. Ocimum sanctum essential oil and its active principles exert their antifungal activity by disrupting ergosterol biosynthesis and membrane integrity. Res Microbiol. 2010;161(10):816-23.

15. Balakumar S, Rajan S, Thirunalasundari T, Jeeva S. Antifungal activity of Ocimum sanctum Linn. (Lamiaceae) on clinically isolated dermatophytic fungi. Asian Pac J Trop Med. 2011;4(8):654-7.

16. Asha MK, Prashanth D, Murali B, Padmaja R, Amit A. Anthelmintic activity of essential oil of Ocimum sanctum and eugenol. Fitoterapia. 2001;72(6):669-70.

17. Pattanayak P, Behera P, Das D, Panda SK. Ocimum sanctum Linn. A reservoir plant for therapeutic applications: An overview. Pharmacogn Rev. 2010;4(7):95-105.

18. Singh S, Rehan HM, Majumdar DK. Effect of Ocimum sanctum fixed oil on blood pressure, blood clotting time and pentobarbitoneinduced sleeping time. J Ethnopharmacol. 2001;78(2-3):139-43.

19. Franz C. Genetics. In: Hay RKM, Waterman PG editors. Volatile Oil Crops: Their Biology, Biochemistry and Production. Harlow: Longman Scientific \& Technical; 1993. pp. 63-96.

20. Miliauskas G, Venskutonis PR, van Beek TA. Screening of radical scavenging activity of some medicinal and aromatic plant extracts. Food Chem. 2004;85(2):231-7.

21. Saharkhiz MJ, Ghani A, Hassanzadeh Khayyat M. Changes in essential oil content and composition of Clary Sage (Salvia sclarea) Aerial Parts during different phenological stages. Med Aromat Plant Sci Biotechnol. 2009;3(1):90-3.

22. Mohammadi S, Saharkhiz MJ. Changes in Essential Oil Content and Composition of Catnip (Nepeta cataria L.) During Different Developmental Stages. J Essent Oil Bear Pl. 2011;14(4):396-400.

23. Ghani A, Saharkhiz MJ, Hassanzadeh M, Msaada K. Changes in the Essential Oil Content and Chemical Compositions of Echinophora platyloba DC. During Three Different Growth and Developmental Stages.J Essent Oil Bear Pl. 2009;12(2):162-71.

24. British Pharmacopoeia.London: HMSO; 1988.

25. Adams RP. Identification of Essential Oil Components by Gas Chromatography/mass Spectrometry. 4 edCarol Stream: Allured Publishing Corporation; 2007.

26. Clinical and Laboratory Standards Institute (CLSI). Methods for dilution antimicrobial susceptibility tests for bacteria that grow aerobically; Approved Standard. 7 edWayne: Pennsylvania; 2006.

27. Clinical and Laboratory Standards Institute (CLSI). Reference method for broth dilution antifungal susceptibility testing of filamentous fungi; Approved Standard.Pennsylvania: Wayne; 2006.

28. Saharkhiz MJ, Ghani A, Khayat M. Changes in essential oil composition of Clary sage (Salvia sclarea L.) aerial parts during its phenological cycle. Med Aromat Plant Sci Biotechnol . 2009;3:90-3.

29. Amber K, Aijaz A, Immaculata X, Luqman KA, Nikhat M. Anticandidal effect of Ocimum sanctum essential oil and its synergy with fluconazole and ketoconazole. Phytomedicine. 2010;17(12):921-5.

30. Vasudevan DM, Kedlaya R, Deepa S, Ballal M, Geeta. Activity of Ocimum sanctum (the traditional Indian medicinal plant) against the enteric pathogens. Indian J Med Sci. 2001;55(8):434-8.

31. Shokeen P, Bala M, Singh M, Tandon V. In vitro activity of eugenol, an active component from Ocimum sanctum, against multiresistant and susceptible strains of Neisseria gonorrhoeae. Int J Antimicrob Agents. 2008;32(2):174-9.

32. Cunha BA. Pseudomonas aeruginosa: resistance and therapy. Semin Respir Infect. 2002;17(3):231-9.

33. Khoshpey B, Farhud D, Zaini F. Aflatoxins in iran: nature, hazards and carcinogenicity. Iran J Public Health. 2011;40(4):1-30.

34. Godbole G, Gant V. Respiratory tract infections in the immunocompromised. Curr Opin Pulm Med. 2013;19(3):244-50. 
35. Burt S. Essential oils: their antibacterial properties and potential applications in foods--a review. Int J Food Microbiol. 2004;94(3):22353.

36. Ali SM, Khan AA, Ahmed I, Musaddiq M, Ahmed KS, Polasa H, et al. Antimicrobial activities of Eugenol and Cinnamaldehyde against the human gastric pathogen Helicobacter pylori. Ann Clin Microbiol Antimicrob. 2005;4:20.

37. Chaieb K, Hajlaoui H, Zmantar T, Kahla-Nakbi AB, Rouabhia M Mahdouani K, et al. The chemical composition and biological activity of clove essential oil, Eugenia caryophyllata (Syzigium aromaticum L. Myrtaceae): a short review. Phytother Res. 2007;21(6):501-6.

38. Jadhav BK, Khandelwal KR, Ketkar AR, Pisal SS. Formulation and evaluation of mucoadhesive tablets containing eugenol for the treatment of periodontal diseases. Drug Dev Ind Pharm. 2004;30(2):195-203.

39. Oyedemi SO, Okoh AI, Mabinya LV, Pirochenva G, Afolayan AJ. The proposed mechanism of bactericidal action of eugenol, $\alpha$ terpineol and g-terpinene against Listeria monocytogenes, Streptococcus pyogenes, Proteus vulgaris and Escherichia coli. Afr J Biotechnol. 2009;8(7):1280-6.

40. Gochev VK, Girova TD. Antimicrobial Activity of Various Essential Oils Against Spoilage and Pathogenic Microorganisms Isolated from Meat Products. Biotechnology \& Biotechnological Equipment. 2014;23(sup1):900-4.

41. Devi KP, Nisha SA, Sakthivel R, Pandian SK. Eugenol (an essential oil of clove) acts as an antibacterial agent against Salmonella typhi by disrupting the cellular membrane. J Ethnopharmacol. 2010;130(1):107-15.

42. Devi KP, Sakthivel R, Nisha SA, Suganthy N, Pandian SK. Eugenol alters the integrity of cell membrane and acts against the nosocomial pathogen Proteus mirabilis. Arch Pharm Res. 2013;36(3):28292.

43. Pauli A. Anticandidal low molecular compounds from higher plants with special reference to compounds from essential oils. Med Res Rev. 2006;26(2):223-68.

44. Thompson D, Moldeus P. Formation and reactivity of a quinone methide in biological systems. Adv Exp Med Biol.1991;283:589-96.

45. Gill AO, Holley RA. Mechanisms of bactericidal action of cinnamaldehyde against Listeria monocytogenes and of eugenol against L. monocytogenes and Lactobacillus sakei. Appl Environ Microbiol. 2004;70(10):5750-5.

46. Govinden-Soulange J, Magan N, Gurib-Fakim A, Gauvin A, Smadja J, Kodja H. Chemical composition and in vitro antimicrobial activities of the essential oils from endemic Psiadia species growing in mauritius. Biol Pharm Bull. 2004;27(11):1814-8.

47. Filippi JJ, Lanfranchi DA, Prado S, Baldovini N, Meierhenrich UJ. Composition, enantiomeric distribution, and antibacterial activity of the essential oil of Achillea ligustica All. from Corsica. J Agric Food Chem. 2006;54(17):6308-13.

48. Nascimento AM, Brandao MG, Oliveira GB, Fortes IC, ChartoneSouza E. Synergistic bactericidal activity of Eremanthus erythropappus oil or beta-bisabolene with ampicillin against Staphylococcus aureus. Antonie Van Leeuwenhoek. 2007;92(1):95-100.

49. Mulyaningsih S, Sporer F, Zimmermann S, Reichling J, Wink M. Synergistic properties of the terpenoids aromadendrene and 1,8-cineole from the essential oil of Eucalyptus globulus against antibiotic-susceptible and antibiotic-resistant pathogens. Phytomedicine. 2010;17(13):1061-6. 